\title{
Reforming energy subsidy in Kuwait: maximizing net benefits and equity compliance
}

\author{
M. A. Alolayan ${ }^{1, *}$, F. M. Albarrak ${ }^{2}$, M. Abotalib ${ }^{3}$, M. A. Alshawaf ${ }^{1}$ \\ ${ }^{1}$ Dept. of Environmental Technology Management, College of Life Sciences, Kuwait \\ University, P. O. Box 5969, Safat 13060, State of Kuwait \\ ${ }^{2}$ Kuwait Environmental Public Authority, P. O. Box 24395, Safat, State of Kuwait \\ ${ }^{3}$ Dept. of Earth and Environmental Sciences, College of Sciences, Kuwait University, \\ P. O. Box 5969, Safat 13060, State of Kuwait \\ *Corresponding author: prof.alolayan@gmail.com
}

\begin{abstract}
The net benefits and public acceptance of a proposed reform to the current subsidization of energy in the State of Kuwait were investigated in this study. The proposed subsidization suggests that the government pays the consumers the subsidization cost in advance and in exchange for raising the subsidized tariffs to total price. The consumption will likely be reduced by a rate equal to the overconsumption due to the current subsidized tariffs relative to the income. The net benefits are expected to be maximized and shifted to a pseudo-equilibrium point where both the governments and the consumers will be better off financially. The public acceptance of the proposed strategy was examined using 274 voluntarily one-to-one interviews for gasoline and 121 for electricity and water. Also, a utility meters reading program was conducted on 90 houses out of the 121 interviews for utilities. The interviews for gasoline and utilities indicated $57 \%$ and $66 \%$ of the respondents see no equity in the current subsidization, $55 \%$, and $80 \%$ admitted to overuse, $11 \%$ and $21 \%$ average of the consumption, and $67 \%$ and $66 \%$ of the respondents were willing to adopt the new strategy. The consumer is expected to save $912 \mathrm{USD} /$ year from gasoline and 8,198 USD/year from utilities. The estimated net benefits are 5,841 million USD annually, with $62 \%$ attributed to utility benefits and $38 \%$ to gasoline benefits.
\end{abstract}

Keywords: Benefits; electricity; energy; subsidization; water

\section{Introduction}

The impact of burning fossil fuels for energy generation on outdoor air quality and public health has been studied thoroughly in many previous studies (Laden, Schwartz, Speizer, \& Dockery, 2006; Alolayan, Brown, Evans, Bouhamra, \& Koutrakis, 2013). These sources are well known to be significant contributors to outdoor air quality (Al-Mutairi \& Koushki, 2009; Ramadan, Al-Sudairawi, \& Khan, 2008). Studies have been consistently confirming the strong association between respiratory and cardiovascular diseases and ambient air quality (Cohen, et al., 2005; Balluz, et al., 2007). In addition, the toxicity of emissions from combustion sources was higher than other sources, sand dust, for instance (Laden, Neas, Dockery, \& Schwartz, 2000; 
Schlesinger \& Cassee, 2003; Cooke, et al., 2007). Therefore, governments and environmental agencies monitor air quality and regulate the sources of emissions to protect public health. Also, they seek to improve public health through improving outdoor air quality because of the health benefits that can justify the cost of control.

The impact of burning fossil fuel on the ambient air quality and, accordingly, public health is increasing remarkably due to the rapid growth in the human population and energy consumption per capita. Although energy can be generated from renewable sources with zero emissions, fossil fuel still dominates the market due to its reliability. For instance, countries small in size, lack coasts, or have few sunny days around the year cannot meet the energy demand by relying on renewable energies only.

Governments have been struggling to improve outdoor air quality without compromising the living standards by using different interventions. For example, public awareness increases the tax on burning fossil fuels, waves the tax on the recycling business, subsidizes renewable energy projects, and bans selling and importing products with low-efficiency energy (Idress \& Shaaban, 2020; Shah, Nawaz, Ahmad, \& Arshad, 2020). Unfortunately, applying such measures is not easy in some circumstances or not enough. Public Acceptance of an intervention plays a significant role; hence it drives and influences the decision-makers. Unfortunately, most of the interventions could lower the public living standards. For instance, raising the gasoline price will make some people buy smaller cars or start using bicycles in cold rainy winter or hot, dusty summer to save money or because they can't afford it. Also, increasing the electricity and water tariffs will make people live in darker houses at night, in hotter or colder environments, and take less often and shorter showers and hot tubs. Therefore, it is challenging to maintain living standards and diminish energy consumption in parallel. The advancement in technology increased the efficiencies of electronics, vehicles, manufacturing etc. However, the advancement generated new usages and has slowed down.

Many studies investigated the benefits of controlling air quality through a cost-benefit analysis and concluded that the benefits exceed the cost of controlling. Not surprisingly, health benefits dominated the total benefits, specifically preventing premature deaths (Cifuentes \& Lave, 1993; McKinley, et al., 2003; United States Enviornmental Protection Agency, 2011).

The state of Kuwait is a rich oil country where gasoline products, water, and electricity are strongly subsidized by the government (Table 1 \& Table 2) (Fattouh \& Mahadeva, 2014; Information, 2017; Kuwait National Petroleum Company, 2015). Such subsidization encourages the consumer to abuse these utilities in a squandering way (World Bank, World Development Indicators, 2013). Not surprisingly, such subsidization would create huge bills and a burden on the government and emanates large emissions into the atmosphere (Figure 1, Figure 2) (Kuwait National Petroleum Company, 2015; Kuwait Petroleum Company, 2015). The public is firmly against raising the tariffs or any action toward lowering this subsidization. The government conducted campaigns to raise public awareness, banned selling inefficient energy products, and subsidized high-energy efficiency products. However, this was not capable of changing the practices by the public or making a significant reduction in consumption. 
Table 1. Water \& electricity tariff in Kuwait as of 2017 (Fattouh \& Mahadeva, 2014;

Information, 2017)

\begin{tabular}{|l|l|l|}
\hline Segment & $\begin{array}{l}\text { Electricity } \\
\text { (Fils/kwh) }\end{array}$ & $\begin{array}{l}\text { Water } \\
\text { (Fils/Imperial gallon) }\end{array}$ \\
\hline Residential & 2 & 0.8 \\
\hline Governmental Facilities & 25 & 4 \\
\hline Industrial \& Farms & 5 & 1.250 \\
\hline Industrial \& Farms (producers) & 3 & 0.75 \\
\hline Investment \& Commercial & 5 & 2 \\
\hline Tankers Filling Stations & -- & 0.5 \\
\hline $\begin{array}{l}\text { Reactive Power for Governmental } \\
\text { Facilities, Industrial and Commercial }\end{array}$ & 3 & -- \\
\hline Others & 12 & 2 \\
\hline
\end{tabular}

$* 1$ fils $=0.001 \mathrm{KWD}=0.0033 \mathrm{US} \$$

Table 2. Gasoline types (octane number) and prices (KWD/Liter) in Kuwait (Kuwait National Petroleum Company, 2015)

\begin{tabular}{|l|l|l|l|}
\hline Premium (No. 91) & Super (No. 95) & Ultra (No. 98) & Diesel \\
\hline 0.085 & 0.105 & 0.165 & 0.100 \\
\hline
\end{tabular}

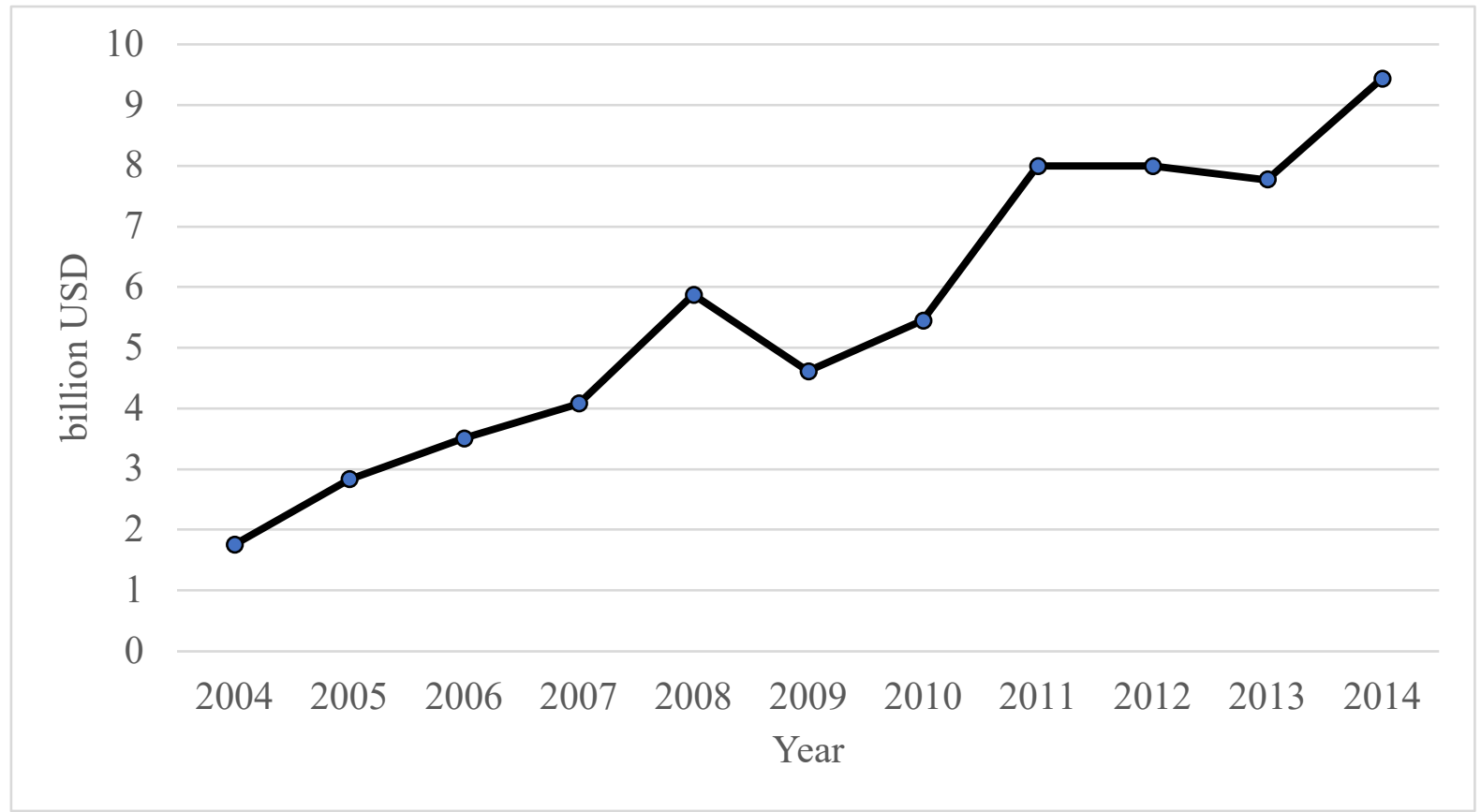

Fig. 1. Cost of all types of fossil fuels used to generate electricity and water in Kuwait over the years (Kuwait Petroleum Company, 2015) 


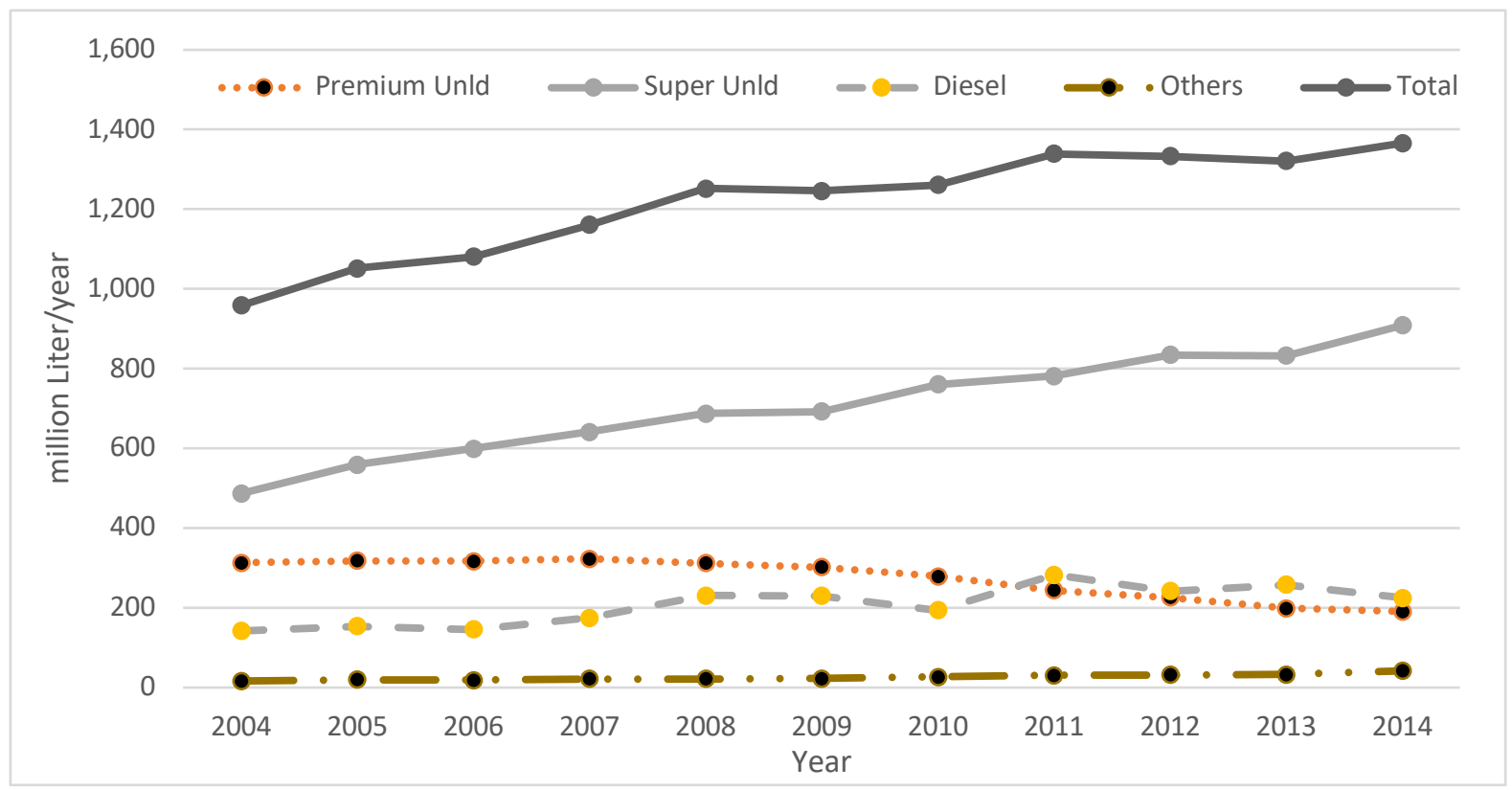

Fig. 2. Quantities of petrol products sold in all gas stations in Kuwait (Kuwait National Petroleum Company, 2015)

Kuwait's current subsidization structure of energy needs to be revised for two reasons. First, the net benefits can be maximized without compromising anyone's net benefit; no one will be worse off. When no loser but a winner results from shifting to a new structure, switching to the new system should be taken to maximize the total benefits. Shifting should continue until pseudo-equilibrium is reached. The total benefits cannot be maximized further at pseudoequilibrium without making someone worse-off. In our case, there are the government and the public, and each seeks to maximize its utility. If a new structure of subsidization is proposed to maximize the total benefits, both should agree on shifting. Therefore, no shifting will be taken if someone is worse off unless the winner agrees to compensate the loser.

Second, the current subsidization generates inequity; hence the benefits are unequally allocated across the population. In fact, by applying the current subsidization, those who consume more will benefit more. There are consumers who enjoy the benefits of gasoline, water, and electricity subsidization more than others. For example, there are consumers who own more cars, bigger cars, drive more, and don't go on extended vacation often. Similarly, some consumers own larger or more houses. Therefore, utility consumption will be way more than the consumer who owns a single small apartment or the citizen who does not own any real estate. Many large houses are owned by a few owners and consist of rented apartments. In Kuwait, it is common that the landlord pays the utility bill. Therefore, the owner is enjoying strong subsidization on all his properties.

The authors of this study investigated an opportunity of reforming the current subsidization structure of electricity, water, and gasoline in Kuwait to reach a pseudo-equilibrium. The proposed restructuring will improve ambient air quality, enrich the country's prosperity, and obtain equity compliance across the population. In addition, this study investigated the public acceptance and estimated the economic value of the proposed subsidization. 


\section{Background}

Air sampling program followed by a source apportionment analysis was conducted in Kuwait to examine the outdoor air quality and investigate the primary sources that contribute to the fine particles level in the atmosphere of Kuwait (Alolayan, Brown, Evans, Bouhamra, \& Koutrakis, 2013; Brown, Bouhanrah, Lamourex, Evans, \& Koutrakis, 2008). The sampling program reported 130 and $53 \mu \mathrm{g} / \mathrm{m}^{3}$ annual averages for $\mathrm{PM}_{10}$ and $\mathrm{PM}_{2.5}$ for Kuwait. These levels exceed the guidance of outdoor air quality for the World Health Organization by factors of six and five, respectively (Organization, n.d.). Also, the daily measurements were more significant than the limits in more than $78 \%$ of the samples. On the other hand, the source apportionment analysis estimated the contribution of local power plants and local traffic to $\mathrm{PM}_{2.5}$ as $18 \%$ and $11 \%$, respectively. The contribution of sand dust and storms was estimated to be around 50\% (Alolayan, Brown, Evans, Bouhamra, \& Koutrakis, 2013). This indicates a valuable opportunity for improving outdoor air quality and, accordingly, public health. The positive association between reduction in $\mathrm{PM}_{2.5}$ and mortality and morbidity was well studied in many studies (Brunekreef \& Forsberg, 2005). This association was stronger with $\mathrm{PM}_{2.5}$ than with $\mathrm{PM}_{10}$ (Schwartz, Dockery, \& Neas, 1996). Two of the most widely cited and influential cohort studies are the Harvard six cities study and the American Cancer Society (Pope 3rd, et al., 2002; Laden, Schwartz, Speizer, \& Dockery, 2006). The effect estimates are $1.5 \%$ and $0.58 \%$ reductions in all-cause mortality rate per $1 \mu \mathrm{g} / \mathrm{m}^{3}$ reduction in the $\mathrm{PM}_{2.5}$ level, respectively. The U.S. EPA used a $1.06 \%$ decrease in all-cause mortality rate per $1 \mu \mathrm{g} / \mathrm{m} 3$ in their report of the benefits and cost of the Clean Air Act between 1990 and 2020 (United States Enviornmental Protection Agency, 2011).

The Gross Domestic Product per Capita for Kuwait is one of the highest globally (around 71,943 USD according to the World Bank in 2017 and 69,669 USD according to the International Monetary Fund in 2107) (World Bank, GDP per Capita PPP (current international\$), World indicators database, 2017; International Monetary Fund, 2017). According to the Ministry of Finance in its report of "Kuwait Closing Accounts 2017/2018," fossil fuels contributed to total country revenues by around $90 \%$, while the deficit in the budget is 4.847 billion $\mathrm{KD}(\sim 16$ billion USD). The Kuwaiti government subsidizes water and electricity by around $95 \%$. On the other hand, the government-subsidized the gasoline by around $90 \%$ until 2016, when the subsidization lowered to around $85 \%$. The Ministry of Electricity \& Water, in its annual report for 2019, indicated that the country burns around $12 \%$ of its total oil production to generate and supply its local demand for electricity and water (Water, 2019 Electrical Energy - Statistical Year Book, 2020; Water, The Annual Statisitcs for Water: 2019, 2020). Because the entire population from 1989 to 2019 increased by $36 \%$ (4.4\% per year), the electricity and water consumption over the same period increased by $247 \%(8.2 \%$ per year) and 596\% (14.9\% per year), respectively (Figure 3). As a result, the per capita electricity and water consumption in 2019 is $14,000 \mathrm{kWh}$ per year and 414 liters per day. The world bank in 2013 reported energy consumption per capita as one of the development indicators (World Bank, World Development Indicators, 2013). Kuwait was ranked fifth place in the list of the highest countries of consumption for the energy per capita. 


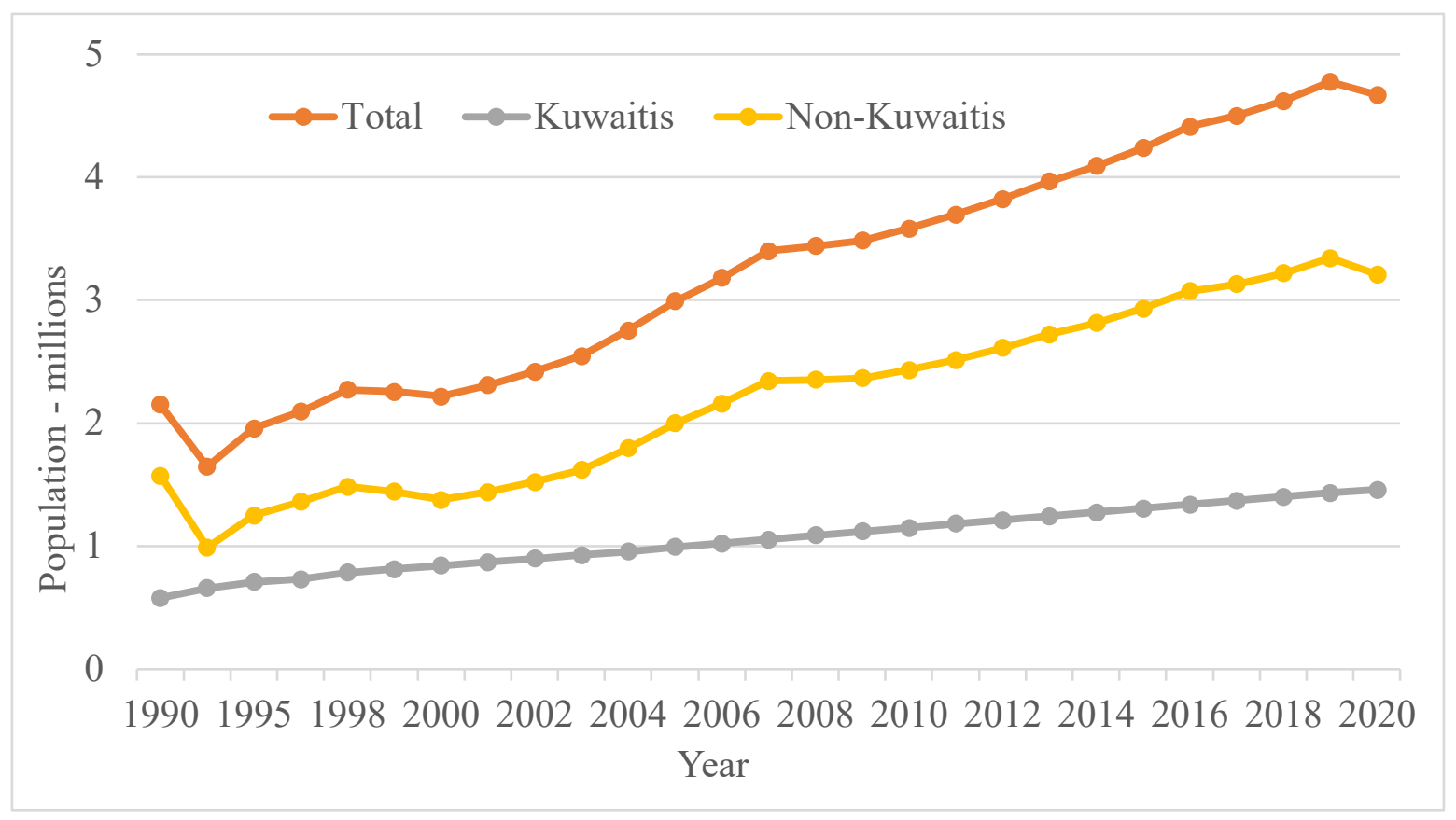

Fig. 3. Total population growth in Kuwait over time (The Public Authority for Civil Information, 2017)

\section{Methods}

The proposed subsidization structure in this study suggests that the government raises the tariffs of electricity, water, and gasoline to the total cost in exchange for compensating the consumer with the subsidization amount for each utility. The existing subsidization does not make the utility bills a burden on the consumer relative to his income. The proposed structure will encourage the consumer to reduce his consumption to save money from the vast subsidization amount that would be given to him in advance. By doing so, the total net benefits are expected to be maximized without any additional cost on any of them. Also, they both will be winners and better off. Additionally, the proposed strategy will result in equity compliance across the population.

The expected net benefits from the proposed subsidization include health benefits due to improving public health, reducing consumption, and other minor benefits (Equation 1) However, the minor benefits such as aviation, agriculture, less traffic, road maintenance costsaving, and capital cost saving (prospective power plants, gas stations, wastewater treatment plants) were excluded from the analysis due to limited data. In addition, several cost-benefit analysis studies have shown that the benefits of avoided premature deaths dominate the total benefits by around 70-85\% (Cifuentes \& Lave, 1993; United States Enviornmental Protection Agency, 2011). For the same reason, the morbidity benefits were excluded from the health benefits (Equation 2).

For example, the U.S EPA report of benefits and costs of the Clean Air Act from 1990 and 2020 estimated the total benefits to be 2 trillion USD, with only 65 billion USD in 2020 . The report indicated that $85 \%$ of these benefits were attributable to the prevention of more than 230,000 deaths. Unfortunately, no similar study has been conducted in Kuwait or the region. 
In this study, only the health benefits of avoided premature deaths were included in the study. Therefore, it is expected that the net benefits will be underestimated.

The health benefits units like QALYs (Quality Adjusted Life Year), DALYs (Disability Adjusted Life Year), and Avoided death need to be monetized for justification. Since our analysis included avoided deaths only, the Value of Statically Life (VSL) was used to monetize these benefits. VSL is an estimate of the tradeoff between fatality risk and money. Many studies have been conducted in this field to estimate VSL for the country of community. For instance, The value of statistical life used by the Department of Transportation and Environmental Protection Agency in the United States is 9.6 million USD and 9.1 million USD, respectively (Alolayan, Evans, \& Hammitt, 2017). Many Agencies and governments adopted an estimate for VSL in their cost-benefit analysis for better decisions. The VSL used in the analysis has a value equal to 21.7 million USD [18.1 - 26.1] 90\% CI based on a study conducted in Kuwait used the approach of willingness to pay for a slight reduction in mortality risk through contingent valuation in 2011 (Alolayan, Evans, \& Hammitt, 2017).

Equation 1

Net Benefits $(\$)=$ Health Benefits $(\$)+$ Consumption Reduction $(\$)+$ Others $(\$)$

$\approx$ Health Benefits $(\$)+$ Consumption Reduction $(\$)$

Equation 2

Health Benefits $(\$)=$ Mortality Benefits $(\$)+\operatorname{Morbidity} \operatorname{Benefits}(\$)$

$\approx$ Mortality Benefits(\$)

$\approx$ Expected No. Avoided Premature Deaths X Value of Statistical Life (\$)

Equation 3

Expected No. Avoided Premature Deaths = Annual Deaths X [1 -

$\mathrm{e}^{- \text {Mortality coefficient } \mathrm{X} \Delta \mathrm{PM}_{2.5} \text { Concentration }\left(\frac{\mathrm{\mu g}}{\mathrm{cm}^{3}}\right)}$ ]

Equation 4

$\Delta \mathrm{PM}_{2.5}$ Concentration $\left(\frac{\mu \mathrm{g}}{\mathrm{cm}^{3}}\right)=$

Avg. Overuse (\%) X Source Contribution to $\mathrm{PM}_{2.5}(\%) \mathrm{XPM}_{2.5}$ Background Concentration $\left(\frac{\mu \mathrm{g}}{\mathrm{cm}^{3}}\right)$

Equation 5

Cost of Saving $(\$)=$ Avg. Overuse (\%) X Avg. Utility consumption $\left(\frac{\$}{\text { Year.Consumer }}\right)$ 
One-to-one interviews and a meter readings program for electricity and water were conducted. The sample used in the study included owners of houses in the State of Kuwait who voluntarily participated and were randomly selected. The interviews were used to investigate the public willingness toward the proposed subsidization system. On the other hand, the meters readings program was conducted to investigate the average public consumption and their seriousness and commitment toward their responses in the interviews.

\subsection{Interviews}

The interviews consisted of four sections. First, the respondent's consensus on the voluntary interview was obtained verbally without collecting their name or any information that could be used to link to them. Then, the respondent was asked whether they doubted that the purpose of the interview was not for scientific research. Also, the interview took place only if the respondent paid for gasoline, electricity, or water. The second section collected demographic information about the respondent and their household. The participants were asked about their gasoline consumption in the third section and their water and electricity consumption in the fourth section. In the third and fourth sections, the questions were placed in a sequence meant to take the respondent through four stages.

The first stage included general questions about the consumer's assets, such as the number of cars they own, their house's size, and their average monthly consumption. The second stage was introduced to avoid the participants' bias in their responses, misunderstanding, or absence of intuition to the questions in the third stage. The questions in the second stage were used to prepare the respondent for the third stage questions. These questions are intended to enlighten the respondent about the current subsidization system and its tariff compared to the actual cost. Also, to elaborate the respondent about the benefits of reducing the utility consumption in the country. A list of some of the benefits mentioned earlier was used here. Additionally, there were questions about the respondents' opinions about their current consumption, whether they overuse the utility, and how much they can reduce it. At the end of the second stage, the respondent was questioned whether he considered or not the current subsidization system complied with equity across the population. Examples were given to the respondent here that indicate some consumers who enjoy this subsidization more than others. On the other hand, the questions in the third stage were related to the new proposed subsidization system. After the new proposed subsidization system was explained to the respondent as a program, they were asked whether they were willing to participate in the program. The respondent will be paid the average subsidization amount of the participants from the previous years in advance, at the beginning of each fiscal year, in exchange for charging them the full fare for the utility. The respondent was reminded about the overuse of the utilities if they admitted to previously and the opportunity to save money by reducing their consumption. Moreover, the benefits of lowering the utility consumption for the community were mentioned again.

\subsection{Meters reading program}

In the last stage of the second and third sections, the respondent was offered to participate in a program where meter readings for water and electricity in their house will be taken to estimate his consumption. These readings were taken to estimate the average consumption for 
each utility across the population. Three readings were taken for both water and electricity over four months: at the beginning, after two months, and at the end. The respondents who agreed to participate in the program were divided randomly into three groups. Group A was informed about their electricity and water bills for the four months in the end. Group B was informed about their bills twice after two months and again at the end of the last two months only. Group $\mathrm{C}$ was informed similarly to group B about their bills, except they were promised after two months that they would receive an amount of money as an incentive equal to the drop in their bills in the last two months compared to the first two months bills. This design was intended to examine whether this incentive can significantly reduce consumption.

\section{Results and discussion}

\subsection{Interviews}

A total of 293 one-to-one interviews were completed on a randomly selected sample between April 2016 and March 2017. There are 19 interviews that were excluded from the study because the respondents doubted that the intention of the interview was not for scientific research and instead for political or governmental purposes (Table $3 \&$ Table 4). Only 121 respondents out of the 274 interviews reported paying electricity and water bills and were interviewed for utility consumption.

The respondents considered that the current subsidization system does not comply with equity were $57 \%$ and $66 \%$ for gasoline, water, and electricity, respectively. Moreover, $67 \%$ and $66 \%$ of the respondents were willing to participate in a new similar subsidization program. Most respondents who rejected the new strategy or indicated equity with the current subsidization are owners of large vehicles or houses and have large household sizes. These numbers should encourage the government and consumers to shift the current subsidization system to a pseudo-equilibrium point where the total benefits will be maximized.

Table 2. Demographics and responses to the gasoline subsidization interviews

\begin{tabular}{|c|c|c|c|c|c|c|c|c|c|}
\hline \multicolumn{10}{|c|}{ Number of Interviews $=274($ Females $=50 \%$, Married $=76 \%)$} \\
\hline \multicolumn{10}{|c|}{ Income (KWD/month) } \\
\hline$<750$ & \multicolumn{2}{|c|}{$750-1,250$} & \multicolumn{2}{|c|}{$1,250-1,750$} & $1,750-2,250$ & \multicolumn{2}{|c|}{$2,250-2,750$} & $>2,750$ & Not Reported \\
\hline $11 \%$ & \multicolumn{2}{|l|}{$33 \%$} & \multicolumn{2}{|l|}{$18 \%$} & $11 \%$ & \multicolumn{2}{|l|}{$7 \%$} & $14 \%$ & $5 \%$ \\
\hline \multicolumn{10}{|c|}{ Education Level } \\
\hline \multicolumn{3}{|c|}{$\leq$ Highschool } & \multicolumn{2}{|c|}{ Diploma } & \multicolumn{2}{|l|}{ College } & \multicolumn{2}{|c|}{ Post-College } & Not Reported \\
\hline \multicolumn{3}{|l|}{$10 \%$} & \multicolumn{2}{|l|}{$23 \%$} & \multicolumn{2}{|l|}{$53 \%$} & \multicolumn{2}{|l|}{$14 \%$} & $0 \%$ \\
\hline \multicolumn{10}{|c|}{ Age (years) } \\
\hline \multicolumn{2}{|c|}{ Minimum } & \multicolumn{2}{|c|}{ Maximum } & Average & Median & \multicolumn{2}{|l|}{ Mode } & $\mathrm{SD}$ & Not Reported \\
\hline \multicolumn{2}{|l|}{23} & \multicolumn{2}{|l|}{80} & 38 & 35 & \multicolumn{3}{|l|}{27} & $2 \%$ \\
\hline \multicolumn{10}{|c|}{ Household Size } \\
\hline \multicolumn{2}{|c|}{ Minimum } & \multicolumn{2}{|c|}{ Maximum } & Average & ge Median & \multicolumn{2}{|l|}{ Mode } & SD & Not Reported \\
\hline \multicolumn{2}{|l|}{1} & \multicolumn{2}{|l|}{11} & 4 & 3 & \multicolumn{2}{|l|}{1} & & $2 \%$ \\
\hline
\end{tabular}




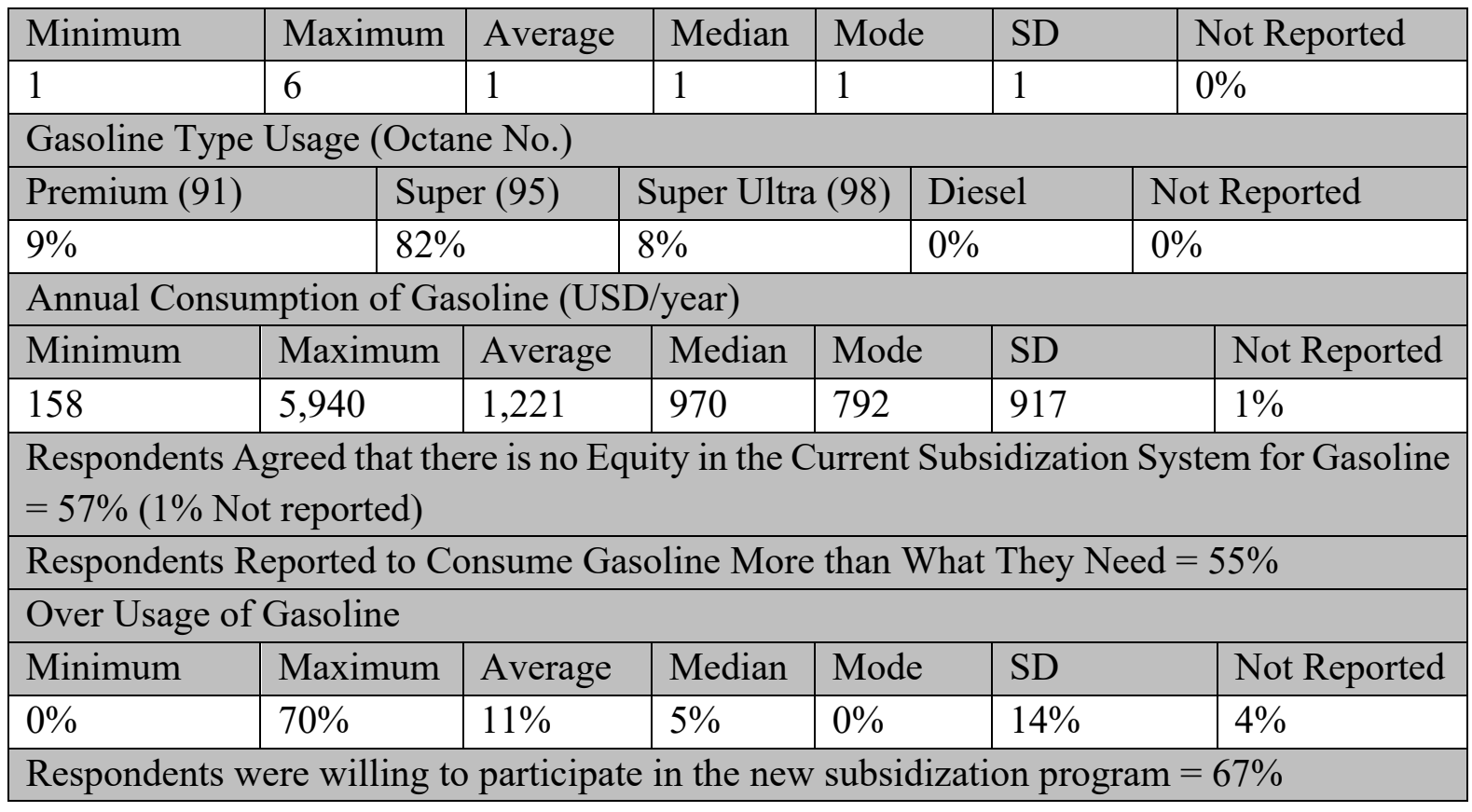

Table 3. Demographics and responses to Electricity and Water Subsidization Interviews

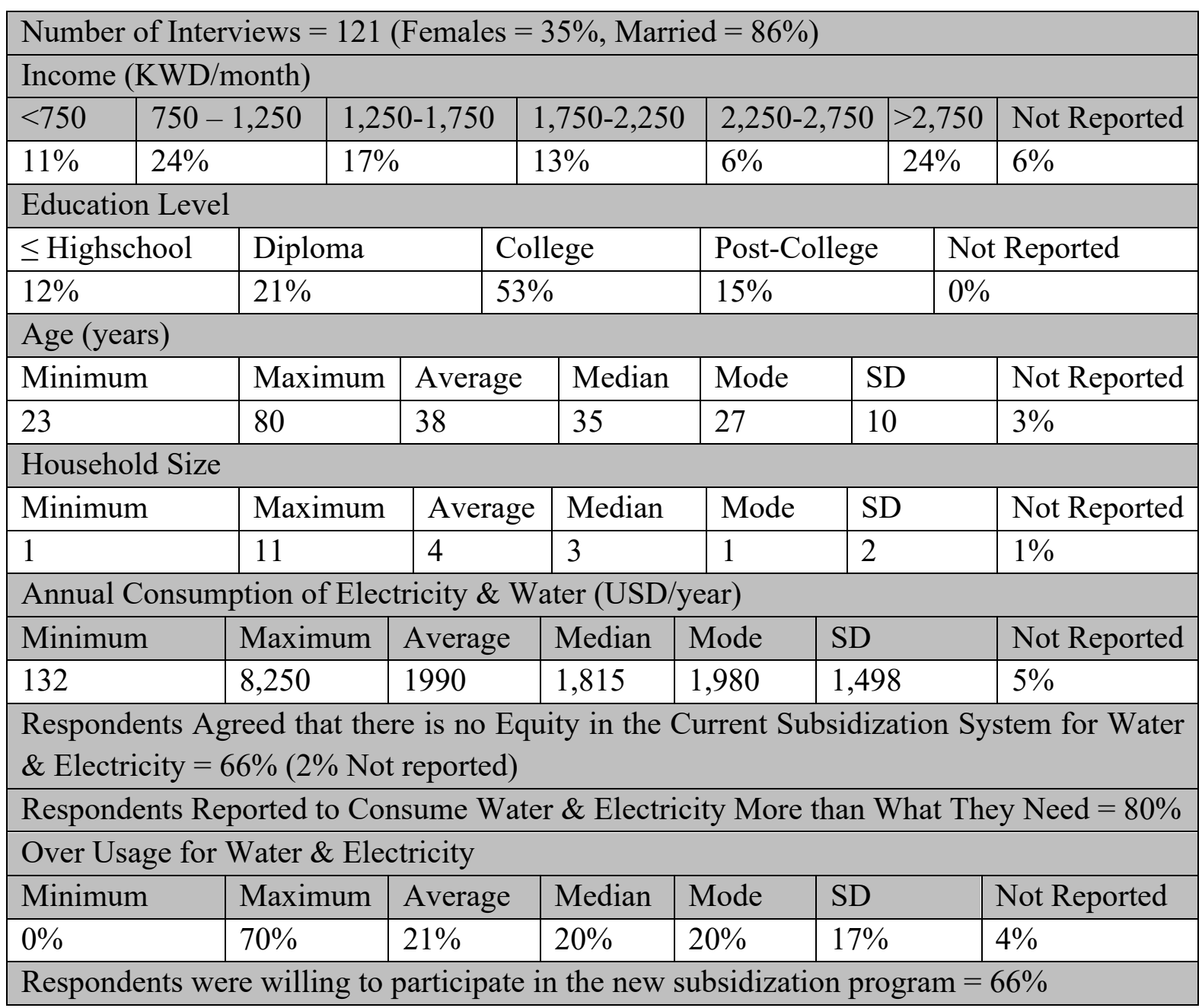


Almost half (55\%) of the respondents admitted consuming more gasoline than needed. The respondents reported an average annual gasoline consumption of 1,221 USD per consumer and $11 \%$ as average overconsumption of gasoline (Table 5). This is equivalent to 136 USD of over usage cost annually per consumer on average. This over-usage cost comprises around $0.2 \%$ only of the consumer income. Therefore, the consumer has no incentive to reduce his consumption for cost-saving. On the other hand, the cost to the government is much higher due to the high subsidization of $85 \%$. Therefore, each consumer will cost the government on average 6,919 USD per year, while the government's annual cost of over usage is 770 USD per consumer. Therefore, the consumer is expecting to save 912 USD annually.

On the other hand, $80 \%$ of the participants reported overusing electricity and water by $21 \%$. As a result, their annual average electricity and water bill is 1,990 USD per consumer (Table 5). Accordingly, the expected over-usage is 410 USD annually for the consumer. Accordingly, the estimated annual cost to the government is 39,800 USD per consumer; hence the subsidization is $95 \%$, and the over usage is 7,788 USD per consumer. Not surprisingly, the over usage cost comprises $0.7 \%$ only of the consumer income. Therefore, the consumer does not expect to save a lot from reducing consumption. On the contrary, it encourages them to abuse it. However, the results suggest that the consumer will be saving 8,198 USD annually.

Table 4. The estimated costs using the interviews' responses (USD/year)

\begin{tabular}{|l|l|l|l|l|}
\cline { 2 - 5 } \multicolumn{1}{c|}{} & \multicolumn{2}{l|}{ Gasoline } & \multicolumn{2}{l|}{ Water \& Electricity } \\
\cline { 2 - 5 } \multicolumn{1}{c|}{} & Average & SE & Average & SE \\
\hline Overconsumption & $11 \%$ & $1 \%$ & $21 \%$ & $1.6 \%$ \\
\hline Total cost on the consumer & 1,221 & 55 & 1,990 & 139 \\
\hline Cost of overuse on consumer & 136 & 12 & 410 & 43 \\
\hline Total cost on the government & 6,919 & 309 & 39,800 & 2,782 \\
\hline Cost of overuse on the government & 770 & 67 & 7,788 & 808 \\
\hline Cost of saving & 912 & 79 & 8,198 & 851 \\
\hline
\end{tabular}

\subsection{Meters reading program}

The meter reading program included 15 owners of apartments and houses from each governorate of the six governorates of the State of Kuwait. The estimated average consumptions of water and electricity across the population from the program were very high (Table 6). However, no significant differences were found in the water and electricity consumptions across groups $\mathrm{A}, \mathrm{B}$, and $\mathrm{C}$ or the governorates. Therefore, neither informing the consumer about his bill nor offering them an amount of money equal the drop in his utility bill were incentives for the consumers to reduce their consumption. This was expected since the tariffs and cost of water and electricity are minimal relative to the income. Therefore, the estimated total cost on the consumer and the government from the meter reading program is not much different from those estimated using the responses to the interviews (Table $5 \&$ Table 6 ). This endorses the quality and credibility of the responses from the participants. 
Table 5. Costs of water and electricity from the meters reading program (USD/year)

\begin{tabular}{|l|l|l|l|l|}
\cline { 2 - 5 } \multicolumn{1}{c|}{} & \multicolumn{3}{l}{ Electricity } & \multicolumn{2}{l|}{ Water } \\
\cline { 2 - 5 } \multicolumn{1}{c|}{} & Average & SD & Average & SD \\
\hline $\begin{array}{l}\text { Average Consumption } \\
\text { (Imperial gallon or kwh/year/consumer) }\end{array}$ & 336,404 & 28,388 & 150,777 & 14,574 \\
\hline Total Cost of Water Consumption (USD/year) & 17,760 & 1,499 & 19,902 & 1,924 \\
\hline Cost on Consumer (USD/year) & 888 & 75 & 997 & 96 \\
\hline Cost on the Government (USD/year) & 16,873 & 1,424 & 18,909 & 1,924 \\
\hline
\end{tabular}

\subsection{Net benefits}

The net benefits analysis was conducted using computer software with a sample size of 1,000 to capture the uncertainty. The analysis was performed twice for gasoline and utilities. Each analysis included the health benefits and the cost of saving.

In the health benefits analysis, $53 \mu \mathrm{g} / \mathrm{m}^{3}$ was used for $\mathrm{PM}_{2.5}$ as a background concentration with a contribution of $18 \%$ due to power plants and $11 \%$ from road emissions. In 2017, the number of deaths and crude mortality rate for the total population in Kuwait were reported by Kuwait Statistical Bure as 6,679 deaths and 1.66 per 1,000 people, respectively (Central Statistical Bureau, 2017). The death rate used is 1.66 per 1,000 , while $1.06 \% / 1 \mu \mathrm{g} / \mathrm{m}^{3}$ from US EPA was used for the mortality coefficient. An adjusted value of VSL was used in the analysis to include the expatriates in Kuwait besides Kuwaitis, with a value of 7.8 million USD. According to the Traffic Department and Public Authority for Civil Information, there are 2.3 million valid driving licenses, around 400,000 residential units, and a total population of 4,670,713 in 2020 (The Public Authority for Civil Information, 2017; Research, 2019).

The expected net benefits are estimated to be 5,841 million USD annually, with $92 \%$ attributed to avoided premature deaths from consumption reduction and $8 \%$ due to cost-saving (Table 7). This is consistent with a similar cost-benefit analysis, which involves health benefits that prevented deaths from dominating the total net benefits. The expected number of avoided premature deaths from consumption reduction for gasoline and utilities are 87 (90\% CI [77,98]) and $160(90 \%$ CI $[140,180])$ deaths annually, respectively. Also, it was found that the estimated benefits from gasoline contribute to the net benefits by $38 \%$, while the electricity and water by $62 \%$. This was expected because both the subsidization and consumption were more significant for utilities than gasoline. Therefore, the annual Concentration of $\mathrm{PM}_{2.5}$ is expected to drop by $3 \mu \mathrm{g} / \mathrm{m}^{3}, 2 \mu \mathrm{g} / \mathrm{m}^{3}$ due to electricity and water, and $1 \mu \mathrm{g} / \mathrm{m}^{3}$ due to gasoline.

Table 6. The expected benefits from the proposed strategy of reforming the subsidization of energy in Kuwait (million USD)

\begin{tabular}{|l|l|l|l|}
\cline { 2 - 4 } \multicolumn{1}{c|}{} & Gasoline & Electricity \& Water & Total \\
\hline Health Benefits & $1,894(236)$ & $3,468(440)$ & $5,363(499)$ \\
\hline Cost of Saving & $315(28)$ & $164(17)$ & $479(33)$ \\
\hline Total & $2,209(253)$ & $3,632(448)$ & $5,841(515)$ \\
\hline
\end{tabular}




\section{Conclusion}

The alluring opportunity of improving the ambient air quality in Kuwait and maximizing the net benefits by only reforming the existing subsidization system for energy was investigated in this study. However, $55 \%$ and $80 \%$ of the samples reported overusing subsidized gasoline and utilities in the interviews, respectively. The reported average overuses are $11 \%$ and $21 \%$ for gasoline and utilities, respectively. Also, $57 \%$ of the sample for gasoline and $66 \%$ for electricity and water agreed that the current subsidization does not comply with equity across the population and encourages the overuse. On the other hand, $67 \%$ and $66 \%$ of the respondents were willing to adopt the new strategy for gasoline and utilities, respectively.

The estimated total net benefit is 5,841 million USD. The annual level of $\mathrm{PM}_{2.5}$ is estimated to drop by $2 \mu \mathrm{g} / \mathrm{m}^{3}$ and $1 \mu \mathrm{g} / \mathrm{m}^{3}$ due to consumption reduction in utilities and gasoline, respectively. Accordingly, $92 \%$ of total net benefits are estimated to be attributable to avoided premature deaths and the remaining to cost-saving. Similarly, $62 \%$ of the total net benefits are due to consumption reduction in the utilities and $38 \%$ for gasoline. The consumer is expected to save $912 \mathrm{USD} /$ year from gasoline and 8,198 USD/year from utilities.

Shifting the current subsidization to a pseudo-equilibrium is highly recommended. The consumers and the government are expected to be better off financially with the proposed subsidization. Also, public willingness toward the new subsidization was investigated. Moreover, the outdoor air quality will improve, which will lead to better public health. Finally, the proposed strategy has complied with the principle of equity.

\section{References}

Al-Mutairi, N., \& Koushki, P. (2009). Potential Contribution of Traffic to Air Pollution in the State of Kuwait. American Journal of Environmental Sciences, 5(3), 218-222.

Alolayan, M. A., Evans, J. S., \& Hammitt, J. K. (2017). Valuing Mortaility Risk in Kuwait: Stated Preference with a New Consistency Test. Enviornmental and Resource Economics, 66, 629-646.

Alolayan, M., Brown, K., Evans, J., Bouhamra, W., \& Koutrakis, P. (2013). Source apportionment of fine particles in Kuwait City. Sci Total Environ, 448, 14-25.

Balluz, L., Wen, X., Town, M., Shire, J., Qualter, J., \& Mokdad, A. (2007). Ischemic heart disease and ambient air pollution of particulate matter 2.5 in 51 counties in the U.S. Public Health Rep., 122(626-633).

Brown, K. W., Bouhanrah, W., Lamourex, D. P., Evans, J. S., \& Koutrakis, P. (2008). Characterization of Particulate Matter for Three Sites in Kuwait. J. Air \& Waste Manage. Assoc, 58, 998-1003.

Brunekreef, B., \& Forsberg, B. (2005). Epidemiological evidence of effects of coarse airborne particles on health. Eur Respir J, 26, 309-318.

Central Statistical Bureau. (2017). Annual Bulletin for Vital Statistics Births and Deaths 2017. State of Kuwait, Central Statistical Bureau. 
Cifuentes, L. A., \& Lave, L. B. (1993, November). Economic Evaluation of Air Pollution Abatement: Benefits from Health Effects. Annual Review of Energy and the Environemnt, 18, 319-342.

Cohen, A. J., Anderson, H. R., Ostro, B., Pandey, K. D., Krzyzanowski, M., Künzli, N., Smith, K. (2005). The Global Burden of Disease Due to Outdoor Air Pollution. Journal of Toxicology and Environmental Health, Part A, 68(13-14), 1301-1307.

Cooke, R., Wilson, A., Tuomisto, J., Morales, O., Tainio, M., \& Evans, J. (2007). A probabilistic characterization of the relationship between fine particulate matter and mortality: Elicitation of European experts. Environ Sci Technol, 41, 6598-6605.

Fattouh, B., \& Mahadeva, L. (2014). Price Reform in Kuwait's Electricity and Water Sector: Assessing the Net Benefits in the Presence of Congestion. The Oxford Institute for Energy Studies.

Idress, A., \& Shaaban, E. (2020). Reforming Home Energy Consumption Behaviour based on Mining Techniques, A Collaborative Home Appliances Approach. Kuwait Journal of Science. Kuwait Journal of Science, 47(4), 29-38.

Information, M. o. (2017, March 26). Decision No. (28)/2017: New Tariffs for Water and Electricity. Kuwait Alyawm.

International Monetary Fund. (2017). World Economic Outlook Database. International Monetary Fund.

Kuwait Petroleum Company. (2015). Fossil Fuel Supply to the Local Power Plants.

Kuwait National Petroleum Company, 2015. Petrol Products Consumption by Local Market.

Laden, F., Neas, L., Dockery, D., \& Schwartz, J. (2000). Association of fine particulate matter from different sources with daily mortality in six U.S. cities. Environ Health Persp, 108, 941-947.

Laden, F., Schwartz, J., Speizer, F. E., \& Dockery, D. W. (2006). Reduction in Fine Particulate Air Pollution and Mortality: Extended Follow-up of the Harvard Six Cities Study. American Journal of Repiratory and Critical Care Medicine, 173, 667-672.

McKinley, G., Zuk, M., Hojer, M., Avalos, M., González, I., Hernández, M., Martínez, J. (2003). The Local Benefits of Global Air Pollution Control in Mexico City. Instituto Nacional de Salud Publica.

Organization, W. H. (n.d.). WHO Air quality guideline values. (World Health Organization) Retrieved July 13, 2021, from https://www.who.int/news-room/factsheets/detail/ambient-(outdoor)-air-quality-and-health

Pope 3rd, C. A., Burnett, R. T., Thun, M. J., Calle, E. E., Krewski, D., Ito, K., \& Thurston, G. D. (2002, Mar 6). Lung cancer, cardiopulmonary mortality, and long-term exposure to fine particulate air pollution. Journal of American Medical Association, 287(9), 1132-1141.

Ramadan, A., Al-Sudairawi, M., \& Khan, S. A. (2008). Total SO2 Emissions from Power Stations and Evaluation of their Impact in Kuwait Using a Gaussian Plume Dispersion Model. American Journal of Environmental Sciences, 4(1), 1-12. 
Research, G. D.-D. (2019). Traffic Statistics. Kuwait City: Ministry of Interior.

Schlesinger, R., \& Cassee, F. (2003). Atmospheric secondary inorganic particulate matter: The toxicological perspective as a basis for health effects risk assessment. Inhal Toxicol, 15, 197-235.

Schwartz, J., Dockery, D., \& Neas, L. (1996). Is daily mortality associated specifically with fine particles? J Air Waste Management Association, 46(10), 927-939.

Shah, S., Nawaz, R., Ahmad, S., \& Arshad, M. (2020). Sustainability Assessment of Modern Urban Transport and Its Role in Emission Reduction of Greenhouse Gases: A Case Study of Lahore Metro Bus. Kuwait Journal of Science, 47(2), 67-81.

The Public Authority for Civil Information. (2017, June). PACI The Public Authority for Civil Information. Retrieved from PACI The Public Authority for Civil Information: https://www.paci.gov.kw/Default.aspx

United States Environmental Protection Agency. (2011). The Benefits and Costs of the Clean Air Act. from 1990 to 2020. Office of Air and Radiation.

Water, M. o. (2020). 2019 Electrical Energy - Statistical Yearbook. Kuwait: Department of Statistics and Information Center.

Water, M. o. (2020). The Annual Statisitcs for Water: 2019. Kuwait: Department of Statistic and Information Center.

World Bank. (2013). World Development Indicators. World Bank.

World Bank. (2017). GDP per Capita PPP (current international\$), World indicators database. World Bank.

Submitted: $\quad 11 / 01 / 2021$

Revised: $\quad 09 / 08 / 2021$

Accepted: $\quad 19 / 08 / 2021$

DOI: $\quad 10.48129 /$ kjs.11837 